\title{
Reimagining Energy Year 2: Integrating CSPs into Course Development
}

\section{Prof. Gordon D Hoople, University of San Diego}

Dr. Gordon D. Hoople is an assistant professor and one of the founding faculty members of integrated engineering at the University of San Diego. He is passionate about creating engaging experiences for his students. His work is primarily focused on two areas: engineering education and design. Professor Hoople's engineering education research examines the ways in which novel approaches can lead to better student outcomes. He is the principal investigator on the National Science Foundation Grant "Reimagining Energy: Exploring Inclusive Practices for Teaching Energy Concepts to Undergraduate Engineering Majors." He has also co-developed a unique interdisciplinary course, Drones for Good, where engineering students partner with peace studies students to design a quadcopter that will have a positive impact on society.

\section{Dr. Joel Alejandro Mejia, University of San Diego}

Dr. Joel Alejandro (Alex) Mejia is an assistant professor of Integrated Engineering at the University of San Diego. His current research investigates how the integration of the historically and culturally accumulated wealth of knowledge, skills, and practices - also known as funds of knowledge - and engineering design can serve as a pathway to and through engineering. Dr. Mejia is particularly interested in how Latinx adolescents bring forth unique ways of knowing, doing, and being that provide them with particular ways of framing, approaching, and solving engineering problems. Dr. Mejia's primary research interests lie at the intersection of engineering education and social justice. He is particularly interested in the integration of Chicanx Cultural Studies frameworks and pedagogies in engineering education, and critical consciousness in engineering through social justice.

\section{Dr. Diana Chen, University of San Diego}

Dr. Diana A. Chen is an Assistant Professor of Integrated Engineering at the University of San Diego. She joined the Shiley-Marcos School of Engineering in 2016. Her research interests are in areas of sustainable design, including biomimicry and adaptability in structural, city, and regional applications. Additionally, her scholarship includes topics such as curriculum development, contextualization of fundamental engineering sciences and integrating social justice into engineering education. She earned her MS and $\mathrm{PhD}$ in Civil Engineering from Clemson University, and her BS in Engineering from Harvey Mudd College.

\section{Dr. Susan M Lord, University of San Diego}

Susan M. Lord received a B.S. from Cornell University in Materials Science and Electrical Engineering (EE) and the M.S. and Ph.D. in EE from Stanford University. She is currently Professor and Chair of Integrated Engineering at the University of San Diego. Her research focuses on the study and promotion of diversity in engineering including student pathways and inclusive teaching. She is Co-Director of the National Effective Teaching Institute (NETI). Her research has been sponsored by the National Science Foundation (NSF). Dr. Lord is among the first to study Latinos in engineering and coauthored The Borderlands of Education: Latinas in Engineering. Dr. Lord is a Fellow of the IEEE and ASEE and is active in the engineering education community including serving as General Co-Chair of the Frontiers in Education Conference, President of the IEEE Education Society, and Associate Editor of the IEEE Transactions on Education (ToE) and the Journal of Engineering Education (JEE). She and her coauthors received the 2011 Wickenden Award for the best paper in JEE and the 2011 and 2015 Best Paper Awards for the IEEE ToE. In Spring 2012, Dr. Lord spent a sabbatical at Southeast University in Nanjing, China teaching and doing research. She is on the USD team implementing "Developing Changemaking Engineers", an NSF-sponsored Revolutionizing Engineering Education (RED) project. Dr. Lord is the 2018 recipient of the IEEE Undergraduate Teaching Award. 


\section{Reimagining Energy Year 2: Integrating CSPs into Course Development}

\section{Overview}

This NSF project focuses on the development of a new, required energy course that considers ways to best include, represent, and honor students from all backgrounds using a collection of pedagogical approaches known as culturally sustaining pedagogies (CSPs). It is sponsored by the Division of Undergraduate Education (DUE) Improving Undergraduate STEM Education: Education and Human Resources (IUSE: EHR) program. Energy is a contemporary and foundational concept across engineering disciplines, but it is often introduced to students in notoriously disengaging Thermodynamics courses. Many of these courses have roots in the Industrial Revolution and are characterized by particularly ethnocentric (White), masculine, and colonial knowledge. CSPs have been used successfully in K-12 settings, yielding particular benefits for traditionally minoritized students, but have yet to be explored in undergraduate engineering. CSPs encourage students to connect their lived experiences to course topics, broaden conceptualizations of energy, and help individuals acknowledge the differing values and perspectives of others.

This research seeks to (1) identify energy examples outside of those traditionally used in thermodynamics; (2) develop and teach a course that integrates these non-traditional examples using CSPs; and (3) deepen educators' understanding of how CSPs impact student learning, mindsets, and attitudes. These materials are being disseminated so that other faculty may use CSPs to engage their students. An overarching goal of this work is to promote inclusion within engineering to support broader participation and thus increase diversity. CSPs may be an important tool in changing the dominant discourse of engineering education, improving the experience for those students already here and making it more welcoming to those who are not.

In the first year of the project we focused on developing our expertise in a range of culturally relevant/responsive pedagogies. We synthesized this learning and presented it in several different forums, including workshops at REES and FIE $[1,2]$.

In the second year of this project, we have focused on developing course materials (e.g., lesson plans, learning outcomes) for our new class based on what was learned in Year 1 about CSPs. This poster and associated short paper report on our progress in course development.

\section{Current Focus of Work: Course Development}

One of the unique features of our team is that the four PIs hold doctorates in four different engineering disciplines: mechanical, electrical, civil, and engineering education. In developing this course we took a holistic approach where we worked collaboratively to develop learning outcomes and course materials. To help guide our course development, we conducted a survey of 
the student body about their interests in energy related topics. That work is being presented in detail at ASEE [3], but two important findings for our course development were 1) students are considerably more interested in renewable energy as opposed to fossil fuel-based energy and 2) students (even seniors) had limited knowledge about energy policy issues.

With this information in hand, coupled with our CSPs framework, we developed the following learning outcomes for our new class:

1. Identify, formulate, and solve engineering problems related to a range of energy concepts (e.g., efficiency, heat, work, and appropriate units)

2. Categorize types of energy using appropriate engineering terminology (e.g., mechanical, internal, solar, electrical, chemical, and nuclear) and perform calculations related to energy transformations

3. Explain the fundamental operating principles of the most common types of electricity generation in California (e.g., natural gas, solar, hydroelectric, nuclear, and wind)

4. Describe contemporary challenges caused by or related to energy resources, such as economic impacts, sociopolitical tensions, and environmental impacts

5. Explain how various methods of both passive (e.g. evaporative cooling) and active (e.g., electric, fuel-powered, heat pumps) heating and cooling in buildings work

6. Analyze how the natural environment (e.g., tree shade, sun angles) and built environment (e.g., windows, insulation) impact heat transfer into and out of buildings, with consideration for cultural and climatic contexts

7. Apply concepts from class to inform decisions about energy consumption or conservation in your everyday life

These learning outcomes reflect several salient aspects from our research into CSPs and related pedagogies. One extremely important element of CSPs is helping students to develop a critical consciousness. This led to the development of learning outcome four, which also aligns well with ABET outcome four. We also discovered from our research into indigenous pedagogy about the importance of place-based education. Therefore we opted to add an element of focus in our class on California's energy landscape, the state where our university is located. Lastly in studying CSPs, we learned about the importance of connecting educational materials to students' lived experiences. Recognizing that energy can often be an intangible concept, we chose to focus a significant portion of the class on the ways in which we use energy in buildings. The goal with these lessons will be to help students see how the structures they live in, and may one day design, interact with our energy landscape.

Throughout these lessons we will be including examples that we hope will broaden our students' conceptions of engineering. Below we describe a few of the examples we are using: 
- Energy as a Social Construction: Rather than provide students with a short (and wrong) definition of the complex thing that is energy, we instead help students see the way in which energy is a social construction. As Robert Lehrman said his 1973 piece Energy is not the ability to do work, "Conservation of energy seems to be a natural law; the description of this law by means of a set of algebraic formulas is a human invention" [4]. We aim to help students see the ways in which engineers talk about energy is not a "universal truth," but is instead a model we have developed over many years.

- Unit Systems are Cultural: Before discussing SI and US Customary units, we include a brief aside about the ways in which unit systems are a cultural phenomenon. We show examples of ancient unit systems from three different cultures, Egypt, Russia, and China. While these systems are all different, they share a common trait (as do most unit systems) that they are based on the human body. This activity helps students to think about WHY units standardization is important, but also the ways in which culture can sometimes resist this standardization.

- Energy efficiency is not the be-all and end-all: Reflection questions that are built into class activities begin to reveal to students that energy efficiency is not always the answer. For example, while the U.S. has a fixation with maximizing the energy efficiency of appliances, much of Europe passively cools buildings by manipulating air flow during certain times of the day. Students learn to consider how heating and cooling are actualized based on culture, climate, and resources.

In our poster, we will also report on how students respond to this approach (this data is currently being collected.). In the final year of the project, we plan to offer the course a second time, improving our pedagogical approach based on learning from our first offering of the course.

\section{References}

[1] Lord, S. M., Mejia, J. A., Luckett, K., Wolmarans, N., and Mochekoane, N. “Decolonizing Engineering Education: Where do we start?," Workshop presented at the 2019 Research on Engineering Education Symposium (REES), Cape Town, South Africa, July 11, 2019.

[2] Lord, S. M., Mejia, J. A., Chen, D. A., and Hoople, G. D., "Starting a Dialogue on Decolonizing Engineering Education," Special Session presented at the 2019 Frontiers in Education (FIE), Cincinnati, OH, October 18, 2019.

[3] Nelson, M., Hoople, G.D., Mejia, J., Chen, D.A., \& Lord, S. (2020). "Work-in-Progress: What is Energy? Examining Engineering Students' Conceptions of Energy", in Proceedings of the American Society for Engineering Education 2020, Montreal, Canada, June 21-24, 2020

[4] Lehrman, R. L. "Energy is not the ability to do work." The Physics Teacher, vol. 11(1), pp. 15-18, Jan. 1973. 


\section{Acknowledgements}

Partial support for this work was provided by the USA National Science Foundation's Improving Undergraduate STEM Education (IUSE) program under Award No. 1836504. Any opinions, findings, and conclusions or recommendations expressed in this material are those of the authors and do not necessarily reflect the views of the National Science Foundation. 